MIGRAÇÃO, TRÁFICO DE PESSOAS E TRABALHO DOMÉSTICO

\author{
Natália Ramos \\ Universidade Aberta de Lisboa (UAB)
}

\title{
MIGRAÇÃO, TRÁFICO DE PESSOAS E TRABALHO DOMÉSTICO
}

Resumo: $O$ artigo destaca que os percursos migratórios são hoje mais complexos, feminizados, qualificados, internacionalizados e individualizados, atingindo todos os continentes, países, géneros, classes sociais e gerações. Considera que eles estão na origem de transformações identitárias, familiares, sociais, laborais, culturais e políticas, implicando os vários domínios da esfera pública e privada. Evidencia que, nas últimas décadas, assistimos não só ao crescimento e diversificação das migrações internacionais, principalmente femininas, como também à generalização e globalização do trabalho feminino migrante, com muitas mulheres migrantes a encontrar trabalho no serviço doméstico. Acrescenta que as migrações, particularmente femininas, o tráfico humano, bem como as desigualdades sociais, laborais e de género, constituem objeto de pesquisa e de preocupação dos Estados, de organismos nacionais e internacionais e das políticas públicas nos diferentes setores. Aponta que importa desenvolver uma abordagem integrada e multi/interdisciplinar das migrações, baseada nos direitos humanos fundamentais e em políticas públicas adequadas, reconhecendo a migração, nomeadamente feminina, como um fator essencial de desenvolvimento, mas também as vulnerabilidades, discriminações e exploração associadas.

Palavras-chave: Migrações no feminino, trabalho doméstico, género, identidades, tráfico humano, políticas públicas.

\section{MIGRATION, HUMAN TRAFFICKING AND DOMESTIC WORK}

Abstract: The human migrations become nowadays more complex, feminized, qualified, internationalized and individualized. The human migration process has been reaching all continents, countries, genders, social classes and generations. They are rooted in the origin of the identity, family, social, industrial, cultural and political changes, involving various fields of public and private spheres. It is possible to witness in recent decades, not only to the growth and diversification of international migration, mostly female, but also, the generalization and globalization of migrant female labor, many women migrants finding work in domestic service. The human migrations, especially the female migration, human trafficking, as well as, the social, labor and gender inequalities are the object of research and concern of the states, national and international organizations and public policies in different sectors. In this context, it is important to develop an integrated and multi/interdisciplinary approach for migration, based mainly, on human rights and appropriate public policies, recognizing migration, especially, the women migration, not only as an essential factor of development, but also, a factor of the vulnerability, discrimination and associated exploration.

Key words: Female migrations, domestic work, gender, identity, human trafficking, public policies.

Recebido em: 20.07.2014. Aprovado em: 22.11.2014. 


\section{INTRODUÇÃO}

Eu não tinha este rosto de hoje, assim calmo, assim triste, assim magro, nem estes olhos tão vazios, nem o lábio amargo [...] Em que espelho ficou perdida a minha face? (MEIRELES, Cecilia. Retrato. In: Poesia Completa).

Asquestõesdasmigrações, nomeadamente femininas, são da maior relevância e atualidade ao nível da pesquisa, formação e intervenção nos diferentes domínios cientíícos, constituindo objeto de preocupação dos profissionais, de muitos Estados, nomeadamente da União Europeia, de vários organismos nacionais e internacionais e das políticas públicas nos diferentes setores. A Organização das Nações Unidas (2006), a Organização para a Cooperação e o Desenvolvimento Económico, tradução de Organisation for Economic Cooperation and Development (2000), a Organização Internacional para as Migrações (INTERNATIONAL ORGANIZATION FOR MIGRATION, 2010), a Organização das Nações Unidas para a Educação, Ciência e Cultura, tradução de United Nations Educational, Scientific and Cultural Organization (2005), a Organização Internacional do Trabalho (2008) e o Conselho da Europa (2001) têm assinalado os múltiplos desafios colocados pelas migrações às estratégias e políticas do século XXI, nomeadamente migratórias, sociais, laborais, familiares e de género, às competências comunicacionais e interculturais e à cooperação transnacional.

Há novas mobilidades e novas configurações dos percursos migratórios no mundo plural contemporâneo em face dos novos contextos, como: a globalização; a urbanização; - envelhecimento demográfico nos países desenvolvidos; o aumento crescente da migração feminina; o turismo internacional; o surgimento de políticas migratórias em países que as não possuíam; a mobilidade gerida por uma governação mundial das migrações; as novas formas de mobilidade qualificada; as necessidades de serviços domésticos e de cuidados às crianças e aos idosos nos países desenvolvidos envelhecidos; os novos meios de comunicação (os media, a internet); as facilidades de deslocação e rapidez dos meios de transporte.

Muitos indivíduos, particularmente mulheres, emigram para fugir da pobreza, da falta de oportunidades, da violência e opressão dentro do próprio núcleo familiar e comunitário, assim como pela vontade de concretizar sonhos, de emanciparse, de alcançar autonomia e independência financeira e afetiva e, ainda, como estratégia para dar melhores condições de vida para os filhos e demais membros da família.

Os percursos migratórios em relação ao passado são hoje mais diversificados, complexos, feminizados, qualificados, internacionalizados e individualizados, atingindo os diferentes continentes, países, géneros, classes sociais e gerações. Eles estão na origem de profundas transformações identitárias, espaciais, territoriais e interculturais e implicam os vários domínios da esfera pública e privada, nomeadamente familiar e laboral, particularmente feminina.

A migração constitui uma fonte de desenvolvimento individual e coletivo, podendo estar igualmente na origem de vulnerabilidades e conflitos identitários, familiares e sociais, de sofrimento psíquico, de depressão e de distúrbios psicossomáticos, não só devido às experiências anteriores à migração, ao processo migratório e de aculturação e às mudanças implicadas, mas também devido às alterações sociolaborais e aos conflitos nos papéis de género, acentuando desigualdades e papéis tradicionais ou alterando-os. Estas situações poderão agravar-se devido ao isolamento, à falta de suporte social, à exclusão social, aos problemas linguísticos/ comunicacionais, à dependência económica e afetiva, às dificuldades de emprego, à precariedade socioeconómica, ao reduzido acesso à educação $\mathrm{e}$ redes de informação e à situação migratória irregular. Estes fatores diminuem a capacidade de autonomia, o poder de decisão e a defesa dos seus direitos e contribuem para o sofrimento psicológico, doença 
mental e física, discriminação, exploração e tráfico humano dos indivíduos migrantes, principalmente das mulheres (ESPIN, 1987; SOTO; SHAVER,1982; RAMOS, 2004; 2006; 2009; 2012; BHUGRA; AYONRINDE, 2004; JANSSENS; BOSMANS; TEMMERMAN, 2005; LAZEAR et al., 2008; HUIJTS; KRAAYKAMPQUE, 2012). Contudo, constatase que no mundo globalizado de hoje, ainda que continuem a existir muitos migrantes que são objeto de medos, preconceitos, violência e exclusão, ainda que muitos destes indivíduos sejam vítimas de exploração e tráfico humano, mulheres e homens continuam a deslocar-se dentro ou para fora dos seus territórios, por motivos económicos, políticos, laborais, de desigualdades sociais e de género, de guerras e conflitos étnicos e religiosos, académicocientíficos, individuais/subjetivos ou de desastres e catástrofes ambientais. A migração constitui assim um fenómeno importante, sobretudo na Europa, na Ásia e na América do Norte, registando-se perto de 1000 milhões de pessoas em situação de mobilidade no mundo. Mundialmente, estima-se que haja 740 milhões de migrantes internos e 240 milhões de migrantes internacionais. Destes migrantes internacionais, cerca de 100 milhões são mulheres, constituindo a feminização das migrações uma das características das migrações contemporâneas. $\mathrm{O}$ número de migrantes internacionais aumentou significativamente. $\mathrm{Na}$ década de 70 do século passado registrava-se apenas 75 milhões. Sóna União Europeia (UE), o número de migrantes provenientes de países extraeuropeus aumentou $75 \%$ desde 1980 , sendo a Europa o continente que acolhe 0 maior número de migrantes no mundo e o continente mais feminizado. Os que migram devido à insegurança, catástrofes, guerra ou motivos políticos são cerca de 14 milhões. As migrações forçadas de pessoas, geralmente tráfico de mulheres e crianças por redes criminosas internacionais, atingem 12 milhões de indivíduos (ORGANISATION FOR ECONOMIC COOPERATION AND DEVELOPMENT, 2012).

Em Portugal, segundo os Censos de 2011, residiam 394.496 indivíduos de origem estrangeira, representando $3,7 \%$ do total de residentes do país. Mais de metade desta população estrangeira é constituída maioritariamente por mulheres (206.410), //sendo os homens 188.086 e $51,6 \%$ residem na região de Lisboa. A maior comunidade estrangeira é a brasileira (28\%), seguindo-se a cabo-verdiana $(10 \%)$, a ucraniana $(9 \%)$, a angolana $(6,8 \%)$, a romena $(6,2 \%)$ e os originários da Guiné-Bissau $(4,1 \%)$. Em Portugal, entre as mulheres estrangeiras, as brasileiras são as mais numerosas, representando $57,9 \%$ da comunidade brasileira. Por outro lado, Portugal tem reforçado a sua diáspora no mundo, nomeadamente feminina, estimando-se que o número de portugueses e descendentes no estrangeiro atinja cerca de 5 milhões de indivíduos (INSTITUTO NACIONAL DE ESTATÍSTICA, 2012).

No contexto europeu atual, a migração feminina representa $53,4 \%$ da população imigrante na Europa (a taxa mais elevada em relação aos outros continentes). A Europa, África, Ásia Central, América Latina e Caraibas constituem as zonas geográficas onde, desde 1960, se tem verificado um grande aumento da emigração feminina. Por exemplo, de acordo com dados do Censo 2010 (INSTITUTO BRASILEIRO DE GEOGRAFIA E ESTATÍSTICA, 2012), $53,8 \%$ dos emigrantes brasileiros no mundo são mulheres.

Assistimos, nas últimas décadas, não só ao crescimento e diversificação das migrações internacionais, principalmente femininas, como também à generalização e globalização do trabalho feminino migrante, com muitas destas mulheres a encontrar trabalho nos cuidados e serviço doméstico (MOROKIVASIC, 1984; ANTHIAS; LAZARIDIS, 2000; CASTLES; MILLER, 2003; YAMANAKA; PIPER, 2005). A economia subterrânea/informal e o trabalho não declarado integram muitas mulheres migrantes, em particular as empregadas domésticas, fatores que vulnerabilizam a sua situação de trabalho, aumentam a exploração e violência física e psicológica e contribuem para a diminuição das percentagens oficiais de atividades femininas. Devese registar que só a partir dos anos 80 , as análises 
das migrações contemplam a variável género, incluindo a participação feminina no processo migratório e laboral e na teoria geral das migrações. A reunificação familiar constitui a principal via de entrada de emigração para a União Europeia e EUA, ainda que os projetos migratórios, principalmente femininos, sejam cada vez mais autónomos e individualizados. Cada vez mais mulheres com diferente escolarização, provenientes de meios urbanos e rurais e de diferentes nacionalidades, emigram sozinhas ou com projetos migratórios independentes da reunificação familiar, enquanto trabalhadoras, chefes de família e suporte financeiro e familiar. Com efeito, a partir sobretudo dos anos 70 , as mulheres passaram a estar representadas na força laboral global. Em 2006, 40\% da mão de obra global era composta por mulheres (INTERNATIONAL LABOUR ORGANIZATION, 2007). No entanto, comparativamente aos homens, os seus salários são mais baixos, têm empregos menos qualificados e altas taxas de desemprego, situação que mantém muitas mulheres numa situação de pobreza, desigualdade e vulnerabilidade, fazendo com que estas representem $60 \%$ da mão-de-obra não qualificada no mundo e contribuindo para a feminização da pobreza (CHOSSUDOVSKY, 1997; BOYD, 2006).

\section{MIGRAÇÃO NO FEMININO E DINÂMICAS IDENTITÁRIAS, SOCIAIS E LABORAIS}

A experiência migratória para muitas mulheres é complexa e ambivalente. A feminização das migrações e a mobilidade familiar promovem mudanças positivas na dinâmica familiar, nos papéis parentais, nas dinâmicas educativas e económicas, favorecem maior autonomia, autoconfiança e capacitação feminina, mas também aumentam riscos, vulnerabilidades, conflitos e violência. Muitas mulheres migrantes são objeto e agentes de mudança e de desenvolvimento no país recetor e de origem, constituem suporte financeiro familiar contribuindo com envios de remessas de dinheiro para o sustento da família nos países de origem, são atores de desenvolvimento e transformação nos países de acolhimento, onde contribuem com o seu trabalho no apoio às famílias autóctones cujas mulheres exercem uma atividade profissional, mantêm múltiplas pertenças e redes transnacionais, desenvolvem novas práticas de cidadania e conquistaram novas identidades e direitos, mas enfrentam, também, novos problemas familiares, identitários, de saúde, discriminação, exploração e violência (KING et al., 2004; RAMOS, 2006; 2008; 2009; 2010; 2012). 0 processo migratório feminino origina identidades plurais e identidades abandonadas e reconstruídas, segundo as suas trajetórias individuais, sociais, culturais e familiares. Muitas mulheres migrantes vivem identidades contestadas e conflituosas e memórias silenciadas e traumáticas, marcadas pelo preconceito, discriminação, exploração, assédio sexual, tráfico, desqualificação social, invisibilidade e violência (WOODWARD, 2001; LEWIN, 2001; BUTLER, 2003; RAMOS, 2004; 2008; 2009; 2011; JOLLY; REEVES, 2005; PEREIRA RAMOS, 2010).

As mulheres, sobretudo as que migram sozinhas, confrontam-se com a solidão, isolamento, sofrimento e culpabilidade, ainda que se sintam mais autónomas do ponto de vista financeiro e das relações conjugais e familiares. Algumas mulheres migrantes no passado e no presente (nomeadamente portuguesas, asiáticas, da América Latina) são obrigadas a deixar os seus filhos no país de origem ao cuidado de familiares, sobretudo mulheres (mães, irmãs, tias, meninas), para cuidarem de outros, principalmente crianças e idosos, nos países de acolhimento, aquilo que alguns autores designam de maternagem transnacional (HONDAGNEU-SOTELO; ÁVILA, 1997), de cadeias globais de assistência ou de cadeias globais de cuidados (HOCHSCHILD, 2000; EHRENREICH; HOCHSCHILD, 2003). Esta situação tem implicações psicológicas, familiares e sociais importantes, particularmente para as mães e para as crianças que ficam, os orfãos das migrações, e repetem-se no tempo (PARRENAS, 2001; 2005; RAMOS, 2004; 2010; 2011; 2012).

No país de acolhimento, 0 trabalho assalariado das mães migrantes, não exercido 
frequentemente no país de origem ou radicalmente diferente, a dupla jornada de trabalho, 0 isolamento familiar e social, novos modos de vida e novas referências socioculturais, por vezes contraditórias, trazem mudanças no estilo de vida, nas práticas reprodutivas e de fecundidade, nomeadamente na diminuição do número de filhos, nas práticas de maternagem, por exemplo, na diminuição do período de aleitamento materno, e socioeducativas, podendo dificultar a vivência da maternidade e educação dos filhos (RAMOS, 2004; 2008; 2009; 2011; 2012). A situação de migração poderá representar uma fonte de ansiedade, stresse, conflito e depressão para a mulher trabalhadora migrante, sobretudo para a mãe, com consequências para a criança, devido às ruturas, ao isolamento, solidão e dúvidas que acompanham esta etapa, bem como à sobrecarga de trabalho.

Também as mulheres trabalhadoras migrantes podem acumular numerosos níveis de discriminação: de género; étnica/cultural; sexual; profissional, pois trabalham frequentemente em empregos onde não são reconhecidas como trabalhadoras formais e que não são protegidos pela legislação sociale caraterizados porfalta de autonomia e grande relação de subordinação; salarial, aceitando piores condições de trabalho e auferindo salários mais baixos que os trabalhadores autóctones; de estatuto migratório, nomeadamente quando não têm a sua situação migratória regularizada para trabalhar legalmente. Na sociedade recetora, a discriminação social e laboral e o não respeito dos direitos humanos fundamentais condenam muitas mulheres migrantes em situação de vulnerabilidade económica e social ao domínio dos serviços domésticos ou de natureza sexual, por exemplo, na indústria do sexo, acentuando os mecanismos de discriminação, precariedade e exclusão sofridos por muitas mulheres trabalhadoras migrantes na sociedade de origem, tanto no plano material quanto no plano simbólico. Encontramos mulheres migrantes que se encontram em situação de exploração laboral e de discriminação, em particular as que desempenham atividades de caráter doméstico e se submetem a jornadas de trabalho excessivas e que, por vezes, se encontram em situação de clandestinidade, vivendo em condições de precariedade de emprego e de vida e sem um reconhecimento dos seus direitos laborais. Noutras situações, encontramos mulheres migrantes inseridas em redes de tráfico humano, geralmente em situação ilegal, de pobreza ou de dependência afetiva, mulheres aliciadas por redes de exploração sexual ou de trabalho escravo, as quais são iludidas por falsas promessas de emprego ou por conceções de amor romântico. Temos também o exemplo de mulheres migrantes obrigadas a deslocarem-se territorialmente e a procurarem refúgio noutra região ou país, devido a conflitos étnicos, políticos ou religiosos, verificando-se situações de exploração sexual nos campos de refúgio ou nos centros de detenção e discriminação e atentados aos direitos humanos no país de acolhimento (ANTHIAS; LAZARIDIS, 2000; ZAHID et al., 2003; RAMOS, 2004; 2006; 2008; INTERNATIONAL ORGANIZATION FOR MIGRATION, 2005; YAMANAKA; PIPER, 2005; COLE, 2007).

A mulher migrante é considerada como força de trabalho competente para realizar o trabalho doméstico remunerado, sendo que se trata de uma atividade socialmente pouco valorizada, invisivel, pouco qualificada, assumida como algo inerente à condição feminina, frequentemente realizada no âmbito da economia informal, sendo as empregadas domésticas frequentemente privadas de acesso aos cuidados de saúde, sociais e de proteção contra 0 despedimento em caso de maternidade, bem como do controlo pelas autoridades responsáveis pela inspeção no trabalho. Regista-se uma procura crescente de trabalhadoras migrantes com diferentes niveis de habilitações para empregos relacionados com trabalhos domésticos e prestação de cuidados, área onde a regulamentação, leis e legislação são escassas ou não são cumpridas. Muitas destas trabalhadoras encontram-se em setores laborais vulneráveis e informais, sujeitas a diversas formas de exploração laboral e salarial, contribuindo para a sua situação de isolamento, insegurança, cargas horárias 
excessivas e/ou acumulação de vários empregos, 0 que dificulta ou impossibilita a utilização dos serviços nos horários de funcionamento dos mesmos, verificando-se frequentemente incompatibilidade dos seus horários de trabalho com os dos serviços. Verifica-se, com efeito, uma crescente procura de trabalhadoras migrantes, com niveis diferentes de habilitações, para empregos relacionados com a prestação de cuidados. No ano 2000, por exemplo, a percentagem de pessoal estrangeiro de enfermagem nos países da Organização para a Cooperação e o Desenvolvimento Económico (OCDE) correspondia a $11 \%$ e a percentagem de médicos era de $18 \%$ (ORGANISATIONFORECONOMICCO-OPERATION AND DEVELOPMENT, 2007). A presença de enfermeiras, baby siters e domésticas estrangeiras permite às mulheres autóctones participar mais ativamente nas atividades laborais, económicas e remuneradas fora de casa, mas, por outro lado tem produzido e mantido um setor da economia marcado por salários baixos, práticas informais, precárias e desvalorizadas de trabalho, relações de submissão e dependência e isolamento (ANDERSEN, 2000; PARRENAS, 2001; EHRENREICH; HOCHSCHILD, 2003). Constata-se que o trabalho doméstico passou de um contexto de recrutamento à escala nacional para uma escala global, verificando-se uma crescente transnacionalidade do setor. A mercantilização das tarefas domésticas e de cuidado é um fenómeno não só cada vez mais global, sobretudo desde finais do século $X X$, mas igualmente cada vez mais associado às mulheres migrantes, muitas delas convertidas em mães substitutivas da infância global. Esta situação renova a questão da transmissão de atividades domésticas e de cuidados, sobretudo no âmbito feminino (NASH, 2012). Como é também reforçado pela OIT (2006), as mulheres continuam a ser, maioritariamente, responsáveis pela economia do cuidado, enquanto parte integrante do trabalho doméstico.

Os trabalhadores domésticos representam $4 \%$ a $10 \%$ dos trabalhadores nos países em desenvolvimento e $2 \%$ nos países desenvolvidos, sendo que $83 \%$ dos trabalhadores domésticos são mulheres. Por exemplo, no Brasil, em 2012, $15 \%$ das mulheres trabalhadoras neste país eram trabalhadoras domésticas. Destas, $11 \%$ eram brancas e aproximadamente $20 \%$, eram negras (INSTITUTO DE PESQUISA ECONÓMICA APLICADA, 2014). Contudo, $40 \%$ dos países não têm nenhuma regularização deste tipo de trabalho (ORGANIZAÇÃO INTERNACIONAL DO TRABALHO, 2012). Segundo este organismo, em Portugal registam-se 175.500 trabalhadores domésticos, dos quais 173.400 são mulheres, significando que mais de $7 \%$ das mulheres empregadas em Portugal trabalham no setor doméstico. Neste país, os serviços domésticos constituem o ramo de atividade mais frequente entre as mulheres imigrantes empregadas, concentrando $20 \%$ do seu total, verificando-se que as trabalhadoras domésticas estrangeiras têm mais propensão que as portuguesas para requerer um contrato de trabalho e a realização de contribuições para a Segurança Social, dado estes elementos serem importantes no processo de regularização junto às autoridades. Aliás, Portugal é o país da OCDE com a maior percentagem de emprego entre as mulheres imigrantes e não migrantes, distinguindo-se dos restantes países da Europa do Sul.

As mulheres encontram-se mais expostas à exploração e violência sexual que os homens, sendo igualmente vítimas de trabalho forçado, o qual está intimamente ligado ao tráfico humano. A OIT (2005) e a Comissão Europeia (2012) têm-se preocupado com a luta contra o tráfico humano, problema transnacional complexo, o qual está relacionado não só com o trabalho forçado, mas também com o trabalho infantil, a migração, a exploração sexual, as desigualdades sociais e de género, a falta de acesso à educação e a discriminação no mundo do trabalho. Estes organismos internacionais têm desenvolvido um conjunto de normas sobre a proteção do trabalho forçado, do trabalho infantil e do trabalho migrante, bem como, sobre políticas de emprego com vista à promoção da igualdade de direitos e de género 
no trabalho, do trabalho digno e de proteção às vítimas de exploração e tráfico humano. Segundo o relatório da Organização Internacional do Trabalho, calcula-se que 12.3 milhões de pessoas exerçam trabalho forçado e, deste número, 2.45 milhões foram traficadas a nível mundial. Estimase que entre 600.000 a 800.000 pessoas são traficadas anualmente para fora dos países de origem, e, destes, $80 \%$ são mulheres e crianças. Aproximadamente $20 \%$ do trabalho forçado é produto do tráfico de pessoas. Em países industrializados, o tráfico de pessoas representa $75 \%$ do trabalho forçado, e, destes, $43 \%$ situam-se na exploração sexual. 0 tráfico humano constitui 0 $3 .{ }^{\circ}$ negócio ilícito mais lucrativo depois das drogas e do armamento, com redes estimadas entre os 7 e os 12 mil milhões de dólares por ano. Estima-se igualmente que as crianças representam 40 a $50 \%$ de todas as vítimas de tráfico (INTERNATIONAL LABOUR ORGANIZATION, 2005; ALIANÇA GLOBAL CONTRA TRÁFICO DE MULHERES, 2006; UNFPA, 2006; ORGANIZAÇÃO INTERNACIONAL DO TRABALHO, 2013).

Em relação a Portugal, em termos de tráfico de seres humanos, em 2013 houve um aumento de casos, tendo sido sinalizadas 308 vítimas, das quais 299 eram cidadãos portugueses e estrangeiros sinalizados em Portugal e 9 cidadãos nacionais sinalizados no estrangeiro, sendo 49 destas vítimas menores. Mais de $50 \%$ das vítimas eram de nacionalidade estrangeira, sobretudo de origem romena (185), mas também nigeriana (18), brasileira (14), búlgara (14), guineense (7) e bósnia/montenegrina (6). A maioria das vítimas registadas em 2013 era do sexo masculino (175), estando este grupo sobretudo associado ao tráfico para fins de exploração laboral (149). No que diz respeito às vítimas do sexo feminino (110), verificase uma distribuição entre dois dos principais tipos de exploração sinalizada: exploração laboral, onde se inclui a exploração doméstica (55), e a exploração sexual (55) (OBSERVATÓRIO DO TRÁFICO DE SERES HUMANOS, 2014).

\section{POLITICAS E ESTRATÉGIAS MIGRATÓRIAS, DE GÉNERO E CONTRA O TRÁFICO HUMANO}

$\mathrm{Na}$ integração, desenvolvimento e bem-estar das famílias e mulheres migrantes são determinantes as atitudes e comportamentos da população de acolhimento e as políticas da sociedade recetora. As migrações têm colocado em âmbito internacional, europeu e nacional numerosos desafios e têm conduzido à implementação de programas, estratégias e políticas para responder às necessidades e proteção destas populações, tendo sido tomadas várias medidas com vista à gestão eficaz das migrações e a políticas efetivas de migração e integração a nível mundial e europeu.

A migração constitui um desafio importante para os Estados, nomeadamente de caráter jurídico, assumindo particular importância a definição dos direitos dos trabalhadores migrantes e das suas famílias. Neste contexto, foi adotada pela Assembleia Geral das Nações Unidas (Resolução n. ${ }^{\circ} 45 / 158$, de 18 de dez. de 1990) a Convenção Internacional sobre a Proteção dos Direitos dos Trabalhadores Migrantes e dos Membros das suas Famílias, que entrou em vigor em 2003. Para o Comité Económico e Social Europeu (2004), esta convenção tem como objetivo

[...] a protecção dos direitos humanos e da dignidade das pessoas que emigram por razões económicas ou laborais em todo o mundo, mediante legislações adequadas e boas práticas nacionais.

A convenção contempla a proteção internacional de determinados direitos humanos fundamentais para todos os trabalhadores migrantes e respetivas famílias definidos na Declaração Universal dos Direitos Humanos (ORGANIZAÇÃO DAS NAÇÕES UNIDAS, 1948).

A Declaração Universal dos Direitos Humanos, adotada em 1948 pela Organização das Nações Unidas (ONU), representa um marco histórico no que se refere à defesa dos direitos humanos fundamentais, reconhecendo a dignidade inerente a todos os seres humanos e a proteção dos 
seus direitos. Entre estes direitos está 0 direito de mobilidade, consagrado no artigo 13. :

\begin{abstract}
Todo o indivíduo tem o direito de circular livremente e escolher a sua residência no interior de um Estado. Todo o indivíduo tem o direito de abandonar o país em que se encontra, incluindo 0 seu, e o direito de regressar ao seu país. (ORGANIZAÇÃO DAS NAÇÕES UNIDAS, 1948).
\end{abstract}

A defesa do direito ao trabalho digno e equitativo está também consignada no artigo $23 .{ }^{\circ}$ desta Declaração da ONU:

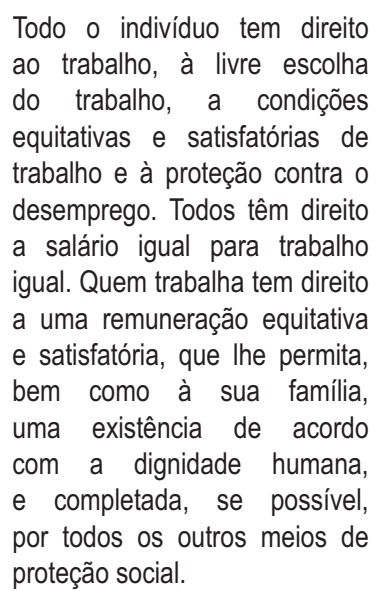

A luta pelo trabalho digno e pela não discriminação de género e no trabalho constitui igualmente um dos objetivos da Organização Internacional do Trabalho e dos Objetivos de Desenvolvimento do Milénio (2000) e tem como finalidade 0 respeito pelos princípios e direitos fundamentais no trabalho, de modo a obter um trabalho produtivo para mulheres e homens autóctones e migrantes, realizado em condições de igualdade, segurança, liberdade e dignidade humana, bem como contribuir para a erradicação da pobreza e violência e para a igualdade de género (INTERNATIONAL LABOUR ORGANIZATION, 1999; 2004a; ORGANIZAÇÃO INTERNACIONAL DO TRABALHO, 2008; 2011; HEPPLE, 2001; DALY, 2001; ELDER; SCHMIDT 2004; CHAPPELL;
MARTINO, 2006). Para combater as desigualdades e discriminações de género a OIT adotou na Conferência Internacional do Trabalho (2004) a Resolução sobre Igualdade de Género, Igualdade Salarial e Proteção da Maternidade, com o objetivo da promoção da igualdade de género nas atividades da OIT. Também para garantir os direitos dos trabalhadores domésticos, onde encontramos muitos indivíduos migrantes, a OIT (2011) adotou a Convenção dos Trabalhadores Domésticos, que procura garantir aos empregados domésticos um conjunto de direitos, de modo a que a sua situação, a este nível, não seja diferente da situação dos outros trabalhadores.

No contexto europeu, a Convenção Europeia de Assistência Social e Médica (1953), ratificada por Portugal em 1977 e a Carta Social Europeia (1961), ratificada por Portugal em 1991, constituem instrumentos fundamentais para a garantia dos direitos de proteção social e de saúde, em situação de igualdade com os nacionais, da população estrangeira residente nos Estados membros do Conselho da Europa.

Em Portugal, várias estratégias e políticas têm sido desenvolvidas no âmbito governamental, tendo em vista a proteção e a promoção dos direitos das populações migrantes, sobretudo das famílias e mulheres migrantes. $O$ Alto Comissariado Para a Imigração e Diálogo Intercultural (ACIDI) incorporou ao Plano para a Integração dos Imigrantes (PORTUGAL, 2010) várias medidas, tendo em vista a promoção da saúde das populações migrantes, bem como dos profissionais que cuidam destes grupos, tais como: promoção do acesso dos imigrantes ao Serviço Nacional de Saúde; plano de formação para a interculturalidade dos profissionais do SNS; implementação de um programa de serviços de saúde amigos dos imigrantes; institucionalização de procedimentos com vista a uma melhor gestão dos acordos de saúde e agilização do acesso dos imigrantes e seus acompanhantes aos serviços de saúde; investimento na promoção da saúde mental dos imigrantes. O ACIDI integrou também neste plano medidas com o objetivo de promover as questões 
de género e dos direitos das mulheres migrantes, nomeadamente: reforço do mainstreaming de género no acolhimento e integração de imigrantes; divulgação, junto às mulheres imigrantes, de informação sobre os seus direitos e deveres específicos enquanto mulheres; capacitação dos agentes de mediação intercultural, no atendimento em serviços públicos, em questões de género e na área da violência doméstica; promoção da participação das mulheres no movimento associativo e na área do empreendedorismo; prevenção da violência doméstica e da violência de género junto dos homens e das mulheres migrantes; desenvolvimento de ações de combate ao tráfico de seres humanos; criação da Rede de Apoio e Proteção a Vítimas de Tráfico de Seres Humanos; encaminhamento e acolhimento para o Centro de Acolhimento e Proteção para Vítimas de Tráfico; consolidação do Observatório sobre o Tráfico de Seres Humanos, nomeadamente a produção, recolha, tratamento e disseminação de informação e conhecimento sobre tráfico de seres humanos e outras formas de violência de género, em colaboração com a coordenação do Plano Nacional contra o Tráfico de Seres Humanos. A título de exemplo o II Plano Contra o Tráfego de Seres Humanos (COMISSÃO PARAA CIDADANIA E IGUALDADE DE GÉNERO, 2013) reforça o combate ao tráfico humano através de 45 medidas visando 4 áreas de intervenção: "[...] conhecer, sensibilizar e prevenir; educar e formar; proteger e assistir; investigar criminalmente e cooperar." (PORTUGAL, 2010). Também o V Plano Nacional para a lgualdade de Género, Cidadania e Não Discriminação 2014-2017 (PORTUGAL, 2013), enquadrando os compromissos assumidos por Portugal nas várias instâncias internacionais, pretende reforçar a intervenção, sobretudo, nos domínios da educação, saúde e mercado de trabalho através de medidas e políticas públicas destinadas a combater as desigualdades de género, a melhorar a situação das mulheres em situação de maior vulnerabilidade, principalmente das mulheres migrantes, e a promover os direitos e a construção da igualdade entre mulheres e homens.
Nos últimos anos, a União Europeia vem desenvolvendo um conjunto de medidas legislativas e não legislativas que permitam combater o tráfico de seres humanos e o trabalho forçado, fenómenos que violam os direitos humanos e impedem 0 desenvolvimento individual, social e económico. Segundo estimativas da OIT (2008), existem no mínimo, a nível mundial, 20,9 milhões de indivíduos vítimas de trabalho forçado, incluindo a exploração sexual e 0 abuso de empregadores pouco escrupulosos, dos quais 5,5 milhões são crianças. Entre os mais vulneráveis, encontram-se as mulheres e as jovens que realizam trabalho doméstico e os trabalhadores migrantes em situação irregular. A União Europeia adotou uma legislação rigorosa que inclui a punição dos indivíduos que exerçam esse tipo de atividade criminosa e ao mesmo tempo permite uma melhor proteção das vítimas. Estas são, muitas das vezes, indivíduos em situação de vulnerabilidade social e psicológica, que vivenciaram experiências dolorosas e traumáticas, as quais necessitam de ser apoiadas e acompanhadas, não só ao nível psicológico, como ao nível da sua reintegração social, familiar e laboral. A Comissão Europeia (2012) desenvolveu uma estratégia integrando 40 medidas para prevenir e combater o tráfico de seres humanos nos próximos anos (2012-2016), bem como para a assistência às vítimas $e \mathrm{a}$ intervenção penal contra os traficantes. Entre essas medidas, destacamse várias iniciativas: apoio à criação de unidades nacionais especializadas no domínio tráfico de seres humanos e responsáveis pela aplicação da lei; criação de mecanismos na União Europeia para uma melhor identificação, proteção e assistência às vítimas de tráfico; criação de unidades conjuntas de investigação, as quais, com o apoio da Europol e da Eurojust, se dediquem à luta contra o tráfico de seres humanos transnacional; criação de uma plataforma de ONGs ativas neste setor, de modo a maximizar os seus esforços e resultados; desenvolvimento de uma coligação europeia de empresas, dedicada a lutar contra o tráfico de seres humanos e contra a utilização de vítimas do tráfico humano no âmbito dos 
contextos económicos europeus; apoio a projetos de investigação sobre a internet $\mathrm{e}$ as redes sociais, fontes de recrutamento cada vez mais utilizadas pelos traficantes; prestação de informações às vítimas sobre os seus direitos ao abrigo da legislação da UE e nacional, sobretudo o direito de assistência e cuidados de saúde, o direito a obter uma autorização de residência, bem como a proteção dos seus direitos laborais.

Para combater 0 tráfico de seres humanos, a União Europeia foi o primeiro organismo internacional a implementar instrumentos legislativos, como: Resolução sobre o Tráfico de Pessoas (Parlamento Europeu,1996); Declaração Ministerial de Haia sobre as Linhas Orientadoras Europeias relativas a medidas efetivas de combate ao tráfico de mulheres para fins de exploração sexual (1997). Para além das normas e legislação, a Comissão Europeia lançou diversos programas, tais como:

- STOP I e II, os quais visam a promoção, apoio e reforço das redes e a cooperação prática entre as agências responsáveis pela intervenção contra o tráfico humano e exploração sexual de menores de idade nos Estados-membros, assim como a melhoria da formação e competências neste domínio;

- DAPHNE I e II, programa de ação comunitária sobre medidas preventivas e de combate à violência infantil, juvenil e feminina, incluindo a exploração e abusos sexuais, tendo como objetivo auxiliar as organizações não governamentais e outras agências na prevenção e assistência às vítimas;

- HIPPOKRATES, programa plurianual de incentivos e intercâmbios de formação e cooperação para a prevenção do crime na União Europeia;

- AGIS, um programa-quadro de substituição dos programas STOP e HIPPOKRATES, o qual tem como objetivo incentivar os Estados-membros a desenvolver a cooperação entre advogados, agentes de segurança e representantes de associações de apoio à vítima, com os países da União Europeia e outros países parceiros, na promoção de redes europeias, intercâmbio de informação e melhores práticas de intervenção.

\section{CONCLUSÃO}

A feminização das migrações internacionais faz parte da nova era das migrações, quer seja no quadro do reagrupamento familiar, quer como migrantes autónomas, sendo fundamental estudar a feminização das migrações e os seus impactos nos países de destino e de origem. É importante reconhecer a migração feminina como uma fonte de inovação e desenvolvimento individual e coletivo, reconhecendo, ao mesmo tempo, os riscos e vulnerabilidades, a discriminação social económica e a exploração laboral e sexual a que esta população está sujeita. As políticas migratórias deverão ter em conta as questões da desigualdade de género, analisar e dar importância aos problemas e necessidades das populações migrantes, assim como à igualdade de género e ao trabalho digno, através de uma abordagem integrada, global e multi/ interdisciplinar da mobilidade humana e do trabalho, baseada nos direitos humanos fundamentais e na formulação de políticas públicas adequadas. Esta abordagem deverá incluir e enfrentar as causas principais das migrações no país de origem, como, por exemplo, a pobreza, a exclusão, as desigualdades, a discriminação, a instabilidade social e política, e deverá integrar estratégias e políticas especificas dirigidas a esta população, tanto nos países de origem como nos países de acolhimento.

A integração e a participação mais igualitária das mulheres, na família, no trabalho e na sociedade, contribuirão para a coesão social, saúde e bem-estar, assim como para a promoção dos direitos, cidadania e igualdade de oportunidades, particularmente das mulheres migrantes. É 
necessário assegurar que as intervenções contra 0 tráfico de seres humanos e exploração sexual, onde um número importante de vítimas corresponde a mulheres migrantes em situação migratória irregular, tenham em conta a dimensão de género e abordem o tráfico essencialmente como uma consequência da ausência de igualdade de oportunidades em termos de emprego e de educação no país de origem, bem como das limitações e fragilidades relacionadas com a governação e regulamentação das migrações

Para reforçar 0 apoio, a proteção, os direitos e a luta contra a exploração e tráfico humano relacionados com a mobilidade das populações, principalmente mulheres e crianças nos países industrializados ou em desenvolvimento, é importante garantir que as políticas migratórias tenham em conta, nomeadamente, os princípios de convenções internacionais, tais como: a Convenção Internacional dos Direitos Humanos (ORGANIZAÇÃO DAS NAÇÕES UNIDAS, 1948); a Convenção dos Trabalhadores Domésticos, (ORGANIZAÇÃO INTERNACIONAL DO TRABALHO, 2011); a Convenção sobre a Eliminação de todas as Formas de Discriminação contra as Mulheres (1979); a Convenção para a Eliminação de Todas as Formas de Discriminação Racial (1965); a Resolução do Parlamento Europeu sobre o Tráfico de Pessoas (1996); a "Declaração Ministerial de Haia de sobre as Linhas Orientadoras Europeias Sobre o Combate ao Tráfico de Mulheres Para Fins de Exploração Sexual" (1997); a Convenção das Nações Unidas contra o Crime Organizado Transnacional (ORGANIZAÇÃO DAS NAÇÕES UNIDAS, 2000).

É necessário aumentar a cooperação entre os governos, as autoridades locais, o setor privado $\mathrm{e}$ as organizações patronais, sindicais, de migrantes $\mathrm{e}$ associações da Diáspora e as ONGs a nível mundial, regional, nacional e local no domínio da migração, igualdade de género e desenvolvimento, bem como quadros consultivos tripartidos, a fim de promover políticas coerentes de migração e garantir a igualdade de oportunidades e de género entre trabalhadores nacionais e trabalhadores migrantes, tanto para as mulheres como para os homens. É importante familiarizar os migrantes com a regulamentação sobre segurança e saúde no trabalho e apoiar a sua integração nas comunidades e locais de trabalho. Torna-se importante proporcionar aos trabalhadores migrantes informação antes da partida sobre as condições culturais, sociais e de trabalho no estrangeiro, meios de proteção social e de saúde, bem como formação relacionada a conhecimentos básicos da língua do país de acolhimento, de modo a facilitar a mudança e integração destes trabalhadores e membros das suas famílias na sociedade recetora. Deverão promover-se medidas adequadas de acesso das mulheres migrantes, aos serviços sociais, educacionais, de saúde e de informação, nomeadamente capacitar sobre a consciencialização dos seus direitos e deveres, facilitar o recurso aos diferentes serviços, promover maior igualdade no trabalho e desenvolver maior equilíbrio entre 0 trabalho e a família. As problemáticas decorrentes das migrações exigem novos modelos conceptuais e metodológicos, políticas públicas e estratégias de intervenção, capazes de gerir a diversidade cultural e a mobilidade humana e de promover e harmonizar a inclusão, os direitos, a cidadania e a igualdade de oportunidades e de género, com a participação, a saúde e o bem-estar de todos os indivíduos, nacionais ou migrantes, em particular, das mulheres migrantes.

Estas abordagens e estratégias teóricas, metodológicas e políticas deverão ter em conta que, no mundo global e interdependente contemporâneo, não é possível viver sem mobilidades, sem solidariedades e com fronteiras fechadas, havendo necessidade de promover competências, políticas públicas e boas práticas, coerentes e concertadas ao nível nacional $e$ transnacional, tanto nos países de origem, de trânsito como de destino. Um mundo sem mobilidades, sem solidariedades, sem respeito pelos direitos humanos e com fronteiras fechadas será um mundo mais pobre e isolado das relações interculturais e interpessoais e dos intercâmbios transnacionais e, portanto, condenado ao empobrecimento, ao envelhecimento e ao declínio. Será também um mundo menos plural, 
menos interativo e aberto à diversidade individual, social, cultural e à alteridade, e, como tal, será um mundo menos desafiante e enriquecedor para o desenvolvimento humano, social e cultural. Será ainda um mundo mais desigual e inseguro, promotor de conflitos, atentados aos direitos humanos, exploração e tráfico humano, fonte de sofrimento, doença, exclusão e violência, sobretudo feminina e familiar.

\section{REFERÊNCIAS}

ALIANÇA GLOBAL CONTRA TRÁFICO DE MULHERES. Direitos Humanos e Tráfico de Pessoas: um manual. Rio de Janeiro, 2006.

ANDERSEN, B. Doing the dirty work?: the global politics of domestic labour. New York: Zed Books, 2000.

ANTHIAS, F.; LAZARIDIS, G. Gender and Migration in Southern Europe: women, on the move. New York: Berg Publishers, 2000.

BHUGRA, D.; AYONRINDE, O. Depression in migrants and ethnic minorities. Advances in Psychiatric Treatment, Leeds, v. 10, p. 13-17, 2004.

BOYD, M. Push Factors Resulting in the Decision for Women to Migrate. In: UNITED NATIONS POPULATION FUND; INTERNATIONAL ORGANIZATION FOR MIGRATION. Female Migrants: Bridging the Gaps Throughout the Life Cycle. New York: UNFPA/IOM, 2006.

BUTLER, Judith. Problemas de gênero: feminismo e subversão da identidade. Rio de Janeiro: Civilização Brasileira, 2003.

CASTLES, S.; MILLER, M. The age of migration. New York: Guilford Press, 2003.

CHAPPELL, D.; MARTINO, V. Violence at work. Geneva: ILO, 2006.

CHOSSUDOVSKY, M. The Globalization of Poverty. London: Zed Books, 1997.

COLE, P. Human rights and the national interest: migrants, healthcare and social justice. Journal of Medical Ethics, London, v. 33, p. 269-272, 2007. COMISSÃO EUROPEIA. Estratégia da União
Europeia para a Erradicação do Tráfico de Seres Humanos 2012-2016. Bruxelas, 2012.

COMISSÃO PARA A CIDADANIA E IGUALDADE DE GÉNERO. II Plano Nacional contra o tráfico de seres humanos - 2012. Porto: CIG, 2013.

COMITÉ ECONÓMICO E SOCIAL EUROPEU. JO $\mathrm{n}^{\circ} \mathrm{C}$ 302, de 7 de Dezembro de 2004. Parecer do Comité Económico e Social Europeu sobre a "Convenção Internacional para os Trabalhadores Migrantes." Brussels, 2004.

CONSELHO DA EUROPA. Diversity and cohesion: new challenges for the integration of immigrants and minorities. Strasbourg, 2001.

DALY, M. (Ed.). Care work: the quest for security. Geneva: ILO, 2001.

EHRENREICH, B.; HOCHSCHILD, A. Global Woman: nannies, maids and sex workers in the new economy. New York: Metropolitan Books, 2003.

ELDER, S.; SCHMIDT, D. Global employment trends for women. Geneva: ILO, 2004.

ESPIN, O. Psychological impact of migration on Latinas: Implications for psychotherapeutic practice. Psychology of Women Quaterly, [S. I.], v. 24, p. 489-503, 1987.

HEPPLE, B. Equality and empowerment for decent work. International Labour Review, Switzerland, v. 140, n. 1, p. 5-18, 2001.

HOCHSCHILD, A. Global care chains and emotional surplus value. In: HUTTON, W.; GIDDENS, A. (Eds). On the edge: living with global capitalism. New York: Free Press, 2000.

HONDAGNEU-SOTELO, P.; AVILA, E. I'm here but I'm there: the meanings of Latina transnational motherhood. Gender and society, [S. I.], v. 11, n. 5, p. 548-571, 1997.

HUIJTS, T.; KRAAYKAMPQUE, G. Immigrants' Health in Europe: a cross-classified multilevel approach to examine origin country, destination country, and community effects. International Migration Review, Malden, USA, v. 46, n. 1, p. 101-137, 2012.

INSTITUTO BRASILEIRO DE GEOGRAFIA 
E ESTATÍSTICA. Estatísticas da População Brasileira. Rio de Janeiro, 2012.

INSTITUTO DE PESQUISAECONÓMICAAPLICADA (Coord.). Objetivos de Desenvolvimento do Milénio: Relatório Nacional de Acompanhamento. Brasília, DF, 2014.

INSTITUTO NACIONAL DE ESTATÍSTICA. A população estrangeira em Portugal. Lisboa, 2012.

INTERNATIONAL LABOUR ORGANIZATION. A global alliance against forced labour: Global report under the follow-up to the ILO Declaration on Fundamental Principles and Rights at Work 2005. In: INTERNATIONAL LABOUR CONFERENCE, 93., 2005, Geneva. Anais... Geneva, 2005. Report I (B).

Decent work: report of the Director-General, International Labour Conference, 87th Session. Geneva, 1999.

Global employment trends for women. Geneva, 2004.

Global employment trends for women: BRIEF. Geneva, 2007.

Report of the Committee of Experts on the Application of Conventions and Recommendations: promoting employment - Policies, skills, enterprises. In: INTERNATIONAL LABOUR CONFERENCE, 92., 2004, Geneva. Anais... Geneva, 2004b. Report III (1B)

Report of the Director-General: Changing patterns in the world of work. In: INTERNATIONAL LABOUR CONFERENCE, 95., 2006, Geneva. Anais... Geneva, 2006. Report I (C).

INTERNATIONAL ORGANIZATION FOR MIGRATION. World Migration Report 2010: the future of migration - building capacities for change. Geneva, 2010.

World Migration 2005: costs and benefits of International Migration. Geneva, 2005.

JANSSENS, K.; BOSMANS, M.; TEMMERMAN, M. Sexual and Reproductive Health and Rights of Refugee Women in Europe. Ghent: ICRH, 2005.

JOLLY, S.; REEVES, H. Gender and Migration: overview report. Prighton: Bridge Institute of Development Studies, 2005.
KING, R. et al. Gender, Age and Generations: state of art report cluster C8. IMISCOE Working Paper, Amsterdam, n. 5, 2004.

LAZEAR, K. et al. Depression among low-income women of colour: Qualitative findings from crosscultural focus groups. Journal of Immigrant and Minority Health, [S. I.], v. 10, p. 127-133, 2008.

LEWIN, F. A. Identity crisis and integration: The divergent attitudes of Iranian immigrant men and women towards integration into Swedish society. International Migration, v. 39, n. 3, p. 121-135, 2001.

MOROKIVASIC, M. Birds of passage are also women. International Migration Review, Paris, ano XVIII, $\mathrm{n}$. 4, p. 21-32, 1984.

NASH, M. Nuevos horizontes y viejos dilemas. Los retos de la era global. In: (Ed.). Mujeres en el Mundo. Historias, retos y movimientos. Madrid: Alianza Editorial, 2012.

OBSERVATÓRIO DO TRÁFICO DE SERES HUMANOS. Tráfico de seres humanos: Relatório 2013. Lisboa: OTSH, 2014.

ORGANISATION FOR ECONOMIC CO-OPERATION AND DEVELOPMENT. Internacional migration. Paris, 2000.

International migration to OECD countries continues to grow in response to labor needs. Paris, 2007.

International Migration. Paris, 2012.

ORGANIZAÇÃODASNAÇÕESUNIDAS. Declaração do Milénio: Objetivos de Desenvolvimento do Milénio - ODM. Nova York, 2000.

Declaração Universal dos Direitos Humanos - DUDH. New York, 1948.

Migrations internationales et développement. New York, 2006.

ORGANIZAÇÃO INTERNACIONAL DO TRABALHO. Convenção N. ${ }^{\circ} 189$ sobre Trabalho Digno para - Trabalho Doméstico. In: CONFERÊNCIA INTERNACIONAL DO TRABALHO, 100., 2011, Genebra. Anais... Genebra, 2011.

Eliminar o trabalho infantil no trabalho doméstico e proteger os jovens trabalhadores das condições de trabalho abusivas. Genebra, 2013. Relatório para o Dia Mundial contra o Trabalho Infantil 2013. Programa Internacional para a Eliminação do Trabalho. 
Igualdade de género no coração do trabalho digno. Genebra, 2008.

OIT Global Estimate of Forced Labour - Results and Methodology. Genebra, 2012. Programa Especial de Ação de Combate ao Trabalho Forçado.

PARRENAS, R. Children of global migration Stanford: Stanford University Press, 2005.

Servants of globalization: women, migration and domestic work. California: Stanford University Press, 2001.

PEREIRA RAMOS, M. C. Migrações e género. Trabalho, empreendedorismo e discriminações. Fazendo Gênero 9. Diásporas, Diversidades, Deslocamentos. Florianópolis: Universidade de Santa Catarina, 2010.

PORTUGAL. Presidência do Conselho de Ministros. Alto Comissariado para a Imigração e Diálogo Intercultural, I. P. II Plano para a Integração dos Imigrantes - 2010-2013. Diário da República, Lisboa, $1^{\text {a }}$ série, n. 182, 2010.

Plano Nacional para a Igualdade de Género, Cidadania e não Discriminação 2014-2017. Resolução do Conselho de Ministros n. $.^{0} 103 / 2013$. Diário da República, $1^{\text {a }}$ série, n. 253, 2013.

RAMOS, N. (Org.). Saúde, Migração e Interculturalidade: perspectivas teóricas e práticas. João Pessoa: EDUFPB, 2008.

Género e Migração. guestionando dinâmicas, vulnerabilidades e políticas de integração e saúde da mulher migrante. In: FAZENDO GÊNERO: diásporas, diversidades, deslocamentos, 9., 2010, Florianópolis. Anais... Florianópolis: UFSC, 2010.

Género e Migração: dinâmicas e políticas sociais, familiares e de saúde. In BOSCHILA, R.; ANDREAZZA, M. L. (Org.). Portuguesas na diáspora: histórias e sensibilidades. Curitiba: EDUFPR, 2011. p. 263-282.

Migração, aculturação, stresse e saúde. Psychologica, Coimbra, v. 41, p. 329-350, 2006.

Migração, Maternidade e Saúde. Reportório:
2012.

Psicologia Clínica e da Saúde. Lisboa: Universidade Aberta, 2004.

Saúde, Migração e Direitos Humanos. Mudanças: psicologia da saúde, São Bernardo do Campo, SP, v. 17, n. 1, p. 1-11, jan.jun. 2009.

SOTO, E.; SHAVER, P. Sex-role traditionalism, assertiveness, and symptoms of Puerto Rican women living in the United States. Hispanic Journal of Behavioral Sciences, [S. I.], v. 4, n. 1, p. 1-19, 1982.

UNITED NATIONS POPULATION FUND. A situação da população mundial 2006: passagem para a esperança - mulheres e migrações internacionais. New York, 2006.

UNITED NATIONS EDUCATIONAL, SCIENTIFIC AND CULTURAL ORGANIZATION. Convention sur la protection et la promotion de la diversité des espressins culturales. Paris, 2005.

WOODWARD, K. Identidade e diferença: uma introdução teórica e conceitual. In: SILVA, T. (Org.). Identidade e diferença: a perspectiva dos estudos culturais. Petrópolis, RJ: Vozes, 2001.

YAMANAKA, K.; PIPER, N. Feminized migration in East and Southeast Asia: policies, actions and empowerment. UNRISD Occasional Paper, Geneva, n. 11, 2005.

ZAHID, M. et al. Psychiatric morbidity among housemaids in Kuwait III: vulnerability factors. International Journal of Social Psychiatry, [S. I.], v. 49, p. 87-96, 2003.

\section{Natália Ramos}

Psicóloga

Doutora e Pós-Doutora em Psicologia pela Universidade Rene Descartes, Paris V, Sorbonne

Coordenadora do Grupo de Investigação "Saúde, Cultura e Desenvolvimento" do Centro de Estudos das Migrações e das Relações Interculturais (CEMIR) da Universidade Aberta de Lisboa (UAB) e Professora Associada do Departamento de Ciências Sociais e de Gestão da UAB

E-mail: natalia@ual.pt

Universidade Aberta de Lisboa - UAB

Rua da Escola Politécnica 141-147, Lisboa, Portugal CEP: 1269-001

Teatro e Dança, Salvador, ano 15, n. 18, p. 84-93, 